\title{
Scholarly communication in transition: The use of question marks in the titles of scientific articles in medicine, life sciences and physics 1966-2005
}

\author{
RAFAEL BALL \\ University Library of Regensburg, 93042 Regensburg, Germany
}

\begin{abstract}
The titles of scientific articles have a special significance. We examined nearly 20 million scientific articles and recorded the development of articles with a question mark at the end of their titles over the last 40 years. Our study was confined to the disciplines of physics, life sciences and medicine, where we found a significant increase from $50 \%$ to more than $200 \%$ in the number of articles with question-mark titles. We looked at the principle functions and structure of the titles of scientific papers, and we assume that marketing aspects are one of the decisive factors behind the growing usage of question-mark titles in scientific articles.
\end{abstract}

\section{Introduction}

The world of scholarly communication has changed dramatically with the increasing number of disciplines. The scholarly output of colleges, universities, and research institutions has virtually exploded over the last few decades. In the ISI databases (Thomson Scientific), for example in the Science Citation Index, there were barely 300,000 articles in 1970 and only 500,000 in 1980, while 10 years later almost 700,000 articles were being accepted every year. The German articles alone have more than tripled in the ISI databases over the last 30 years. However, it is not just the quantity of scholarly communication that has changed; this alone would be a rather banal assertion. More importantly, a change in the formal and qualitative aspects of publications can also be seen. The scope of articles has decreased on the whole, while the use of the English language has increased in all countries.

However, it is not just the measurable parameters of scholarly output that have changed. Time and again, it has been emphasised that the overall quality of articles in the life sciences has deteriorated. Objectively proving this is extremely difficult, if not impossible, particularly since the citation rate has experienced a general increase over the last few decades. Yet, we suspect that many scientists are succumbing to pressure from the "publish or perish" mentality and the performance-oriented allocation of funds and are therefore forced to "recycle" their experimental findings time and again.

Received July 23, 2008; Published online January 31, 2009

Address for correspondence:

RAFAEL BALL

E-mail: rafael.ball@bibliothek.uni-regensburg.de 
In practice this means that a test series and its corresponding interpretations are not just used as the basis for one article, but rather for a number of articles. This segmentation then leads to a flood of smaller and in each case, seemingly less relevant articles.

For all that, in order to gain the required and desired attention amongst the scientific recipients, there are a number of conceivable mechanisms that can be employed. One such mechanism comes from classical marketing and advertising and consists of choosing an attractive, attention-grabbing heading. Traditionally, headings in scientific journals and conference papers are considered "unemotional" titles that directly refer to the contents of the article. In this sense, the intention of the headings of scientific articles is not to generate "subjective emotional" attention but rather to leave the reader "attracted and informed". [1] The following examples are classical titles of medicoscientific publications: "Signal transduction systems regulating fruit ripening" [2], "Huntington's Disease New Paths to Pathogenesis" [3], "History of carbonate ion concentration over the last 100 million years" [4] or even "SynGAP-MUPP1-CaMKII Synaptic Complexes Regulate p38 MAP Kinase Activity and NMDA ReceptorDependent Synaptic AMPA Receptor Potentiation”. [5] [6]

However, in times of scientific mass production, scientific articles are also subject to the competition for attention. This has led to various marketing strategies being employed in this field too in order to win the attention so desperately sought after. "The title...summarises, dramatises and exaggerates". [7]

Titles are therefore extremely important in scholarly communication: Mabe and Armin (2002) found that a scientist today reads an average of 97 articles, 204 abstracts and a staggering 1,142 titles every year. [8]

A general trend away from the use of verb phrases towards the use of noun phrases is also clearly visible in the titles. "Headings are strongly influenced by the constraints inherent in the economy of language and the need to compress as much information as possible into as small a space as possible". [9]

In doing so, each heading should fulfil the following basic functions:

- motivate the reader to read an article

- give the readers a summary of the contents

- $\quad$ give the readers an overview of the topics and findings discussed and

- introduce the way in which the reported items are looked at. [9]

Here, "the priority of the individual functions lies in the advertising effect of the individual announcements. This is the reason why appeal in terms of reader motivation should be top of the list when it comes to function, or it should even be considered on par with the information function" [9]. "A joking title may serve to mitigate the FTA [face threatening act] of a claim. The first announcement of the remarkable and rather unsettling discovery that led to all these other articles I studied is made under an 
unconventional title with a punning use of architecture: Adenovirus-2 messengers - An example of baroque molecular architecture". [10]

There are a range of studies on the titles of scientific publications, for example, on the relationship between the length of the title and the number of authors or the length of the title and how relevant the content is [11]. Lewison and Hartley (2005) looked at the number of words in a title and the use of the colon in the construction of titles and discovered that there has been a clear increase over the last 20 years in titles with a colon. They identified differences in the disciplines and in the countries where the articles were published, but they did not offer a conclusive explanation. [1]

In accordance to Perry, the titular colonicity correlate to the scholarly character of a paper. [12] His and Townsend Mar's [13] findings base on the "Dillon Hypothesis of titular colonicity". [14]

Hartley presented a study on the use of colons in various disciplines and the preferences in reading titles with or without colons. [15]

Soler only identified a low occurrence of titles with question marks. She only took linguistics, medicine and anthropology into account: "As to the question title construction, our counts reveal, in general, a very low occurrence of this title-type". [16] It should also be noted that the sample studied only consisted of a few hundred titles, [16] and the results are therefore not representative.

Using our own test samples, we obtained evidence that structuring the titles of scientific articles as questions is a practice that has blatantly increased over the course of the last few decades, despite the fact that use of question marks in titles is generally discouraged: "Try to avoid questions in the title". [17]

We therefore increasingly come across titles with a wording that would not normally be expected in medico-scientific publications: "Is an infant a people person?" [18], "Do 5-month-old infants see humans as material objects?" [19], "Little Things that Count in Transcriptional Regulation" [20], "What is disrupting IFN- $\alpha$ 's antiviral activity?" [21], "FIBRO-B: the power of love and the love of power" [22], "AKT and cancer-Is it all mTOR?" [23], "What makes a good anti-inflammatory drug target?". [24]

We therefore analysed millions of data entries and filtered out the number of scientific articles whose title ended with a question mark over a period of 40 years in order to determine whether an increase in "question-mark articles" could actually be identified over the course of the years.

\section{Methods}

The present study makes use of Elsevier's Scopus database (http://www.scopus.com/scopus/home.url). The subject of investigation is question marks that appear in the titles of scientific articles. The articles in the database were divided up according to discipline for this analysis. This was done in order to account 
for the fact that different scientific communities have different publication habits. In the following, we will look at articles from the two subject areas "life sciences" and "health sciences" as well as articles from the subject category of "physics". The difference between the subject area of "physical sciences" and the chosen subject category of "physics" is that the subject area is more comprehensive and also includes articles from the field of chemistry, for example. This could cause the results of the evaluation to be distorted.

For the period 1966-2005, all of the data sets that existed when the queries were made (June 2006) were investigated with regard to the presence of a question mark in the title of the article. The question mark did not have to be at the end of the title.

For this purpose, we evaluated 11.15 million data sets in the field of health sciences, 6.38 million data sets in the life sciences, and 1.95 million data sets in physics. These specifications are based on the total number of data sets in these disciplines for the period under investigation from 1966 to 2005.

Since it is not technically possible in Scopus to process such a high number of data sets, all of the analyses were performed online using the advanced search and the results were noted year by year (publication year).

The three designated fields were queried without taking papers classed as "multidisciplinary" into account. In order to achieve this, the subject category "multidisciplinary" was excluded from the search query for the subject areas of "life sciences" and "health sciences" as well as for the subject category of "physics".

The same procedure was used to investigate articles that could be affiliated to a German institution.

In contrast to other databases, the question mark could be queried as a character in SCOPUS and did not function as a truncation symbol. This fact actually made the mass investigation possible in the first place.

\section{Results}

If we compare the results from all of these disciplines (Figure 1), it becomes clear that all of the disciplines (medicine, life sciences and physics) show a clear increase in question-mark articles over the course of the last 40 years.

Of particular note is the increase in question-mark articles in medicine, although the proportion of question-mark articles in medicine was initially quite high in comparison to other disciplines. Even in 1966, the proportion of question-mark articles in medicine was already around $1 \%$, while in the life sciences this proportion was only $0.25 \%$ and in physics it was $0.4 \%$. This increase continued in a fairly linear manner in medicine right up to the $1990 \mathrm{~s}$ when it reached a value of $2.8 \%$ (1989). After this, the increase in the number of question-mark articles accelerated until it reached $5.3 \%$ in 2005 . 


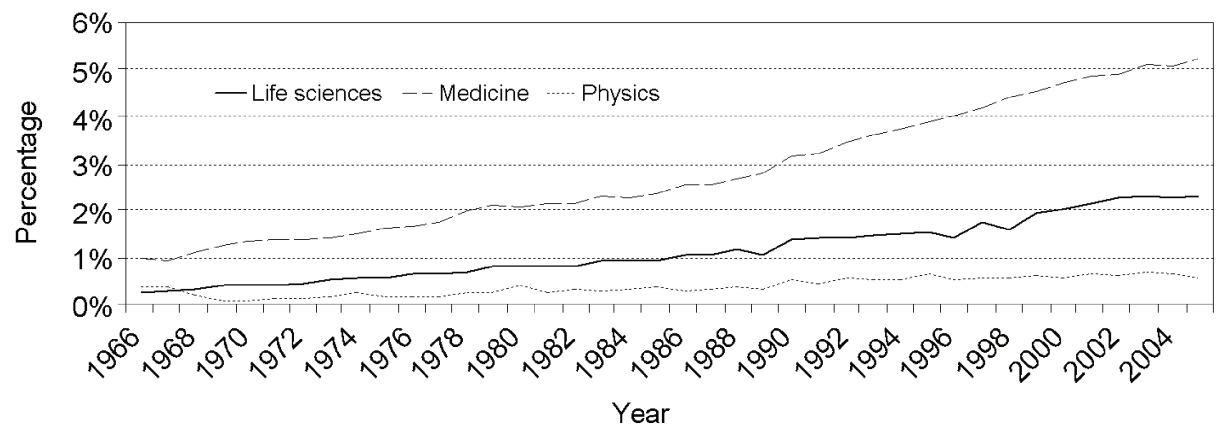

Figure 1 . The disciplines medicine, life sciences and physics show a partly significant increase in question-mark articles worldwide over the course of the last 40 years

This means that one in twenty medical articles published today has a question mark at the end of its title. We were surprised that this figure was so high. If this trend were to continue unchanged for the next few years, then in 20-30 years' time, one in ten medical articles would have a question mark at the end of its title.

A similar trend can also be observed in the life sciences. Here too, a continuous increase can be seen in the number of articles with a question mark at the end of their title. Nevertheless, the increase is moderate in comparison to medicine, and it also starts off from a very low base at the beginning of our analysis period in 1966. At that time, only one in every 400 articles published in the life sciences had a question mark at the end of their title! Nonetheless, this proportion increased to more than $2 \%$ by 2000 and at the end of our analysis period in 2005, it had increased to around 2.3\%. Moreover, the increase has also slowed down dramatically since 2003 . However, we cannot determine a trend here, especially since the progress curve does not behave quite uniformly in the life sciences. Between 1989 and 1998, there were a number of measurable drops in the slope of the curve (Figure 2).

However, on the whole, a clear increase in the number of question-mark articles was determined for the life sciences (continuously over a number of years). In 2005, one in 50 articles in the life sciences had a title that ended with a question mark.

A completely different observation was made for physics. Over the last 40 years, this discipline also showed an increase in the number of articles with a question mark at the end of their titles. In fact, the number of question-mark articles more than doubled on average over the period investigated (from around $0.25 \%$ at the beginning of the data analysis period to $0.5 \%$ in 2005). In comparison to the other two disciplines investigated, however, it should first be noted that physics also began from a very low base, similar to the articles in the life sciences, but that the increase in question-mark articles was smaller than for articles in the life sciences and much lower than articles in 
medicine. While more than $2 \%$ of articles in the life sciences and over $5 \%$ in medicine had a title containing a question mark in 2005, only around a tenth of this figure $(0.57 \%)$ used question marks in physics. The trend in the use of question-mark titles is obviously a discipline-dependent phenomenon.

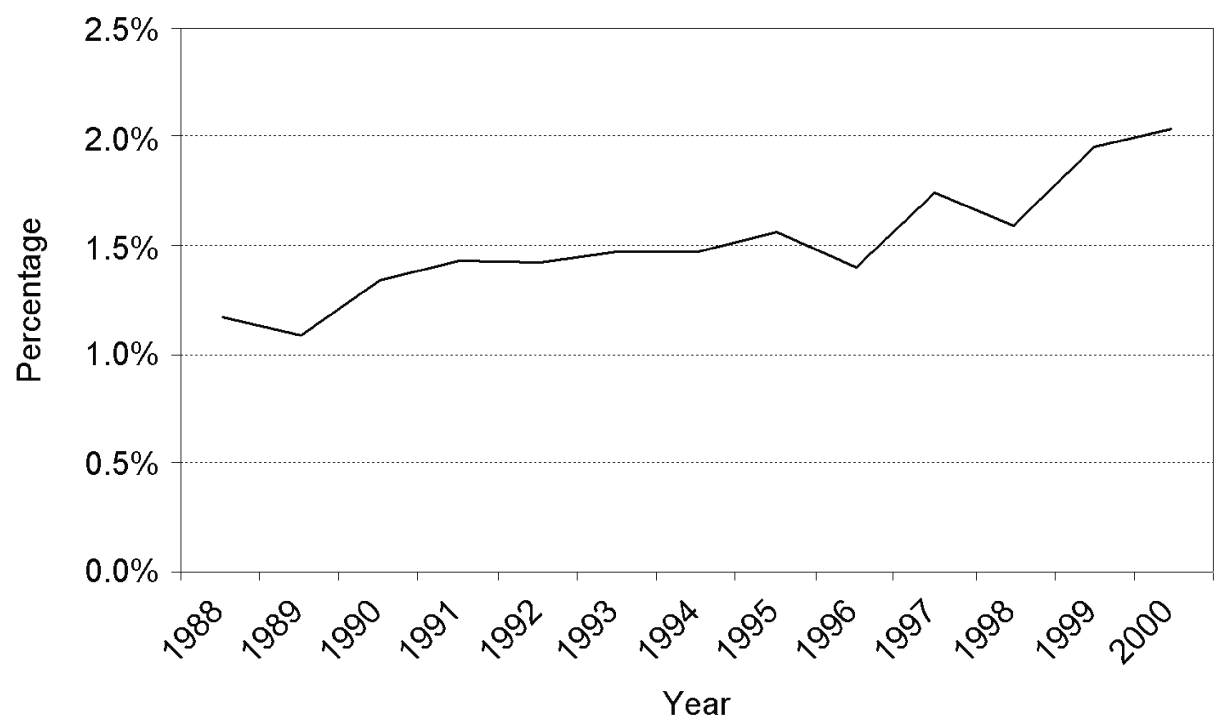

Figure 2. Continuously increase in the number of question-mark articles for the life sciences from 1988-2000

We can offer no concrete explanation for a phenomenon that we identified at the beginning of our measurement series in physics: between 1966 and 1972, we identified a very sharp drop in question-mark articles which almost hit zero. It is only from this time on that the curve begins to climb continuously again. We can only explain this finding in terms of the very small sample available in the database for these particular years. The total number of articles for this period sometimes fell to below 1,000; the number of question-mark articles at times to just one. Against this background, singledigit changes in the number of question-mark articles give rise to massive fluctuations in the relevant percentage data.

In order to find an answer to the question as to whether national differences in the use of the question mark at the end of article titles are plausible, we used articles from Germany as an example. First, we extracted all articles from Germany from the data volume used in this study, and then we analysed them (Figure 3). 


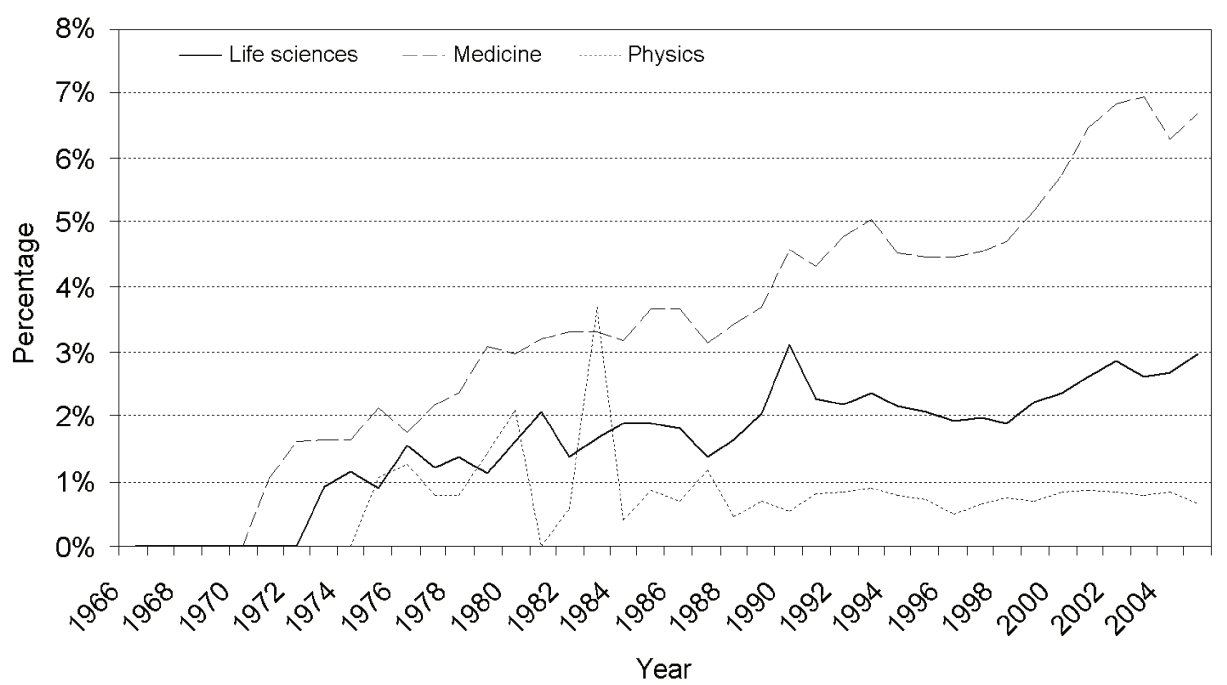

Figure 3. Significant increase in German question-mark articles over the course of the last 40 years

This revealed that articles from Germany tended to follow the global trend. However, important general deviations were determined in terms of the magnitude and continuity of the diagrams obtained.

In medicine, for example, an increase of the same order as the global average could be determined (Figure 4).

However, the increase was initially steeper in the first few years, before increasing in parallel at a figure around 1\% higher. At the end of our data analysis period (2005), there were around $6.7 \%$ question-mark articles amongst the German medical articles, while the global average was $5.2 \%$. Before 1974 in contrast, the database contained no German medical articles. We therefore had to ignore this period.

A similar development to that in medicine was observed in the life sciences. At a figure of around $0.5 \%$ above the worldwide level, the number of question-mark articles in the life sciences from Germany increased parallel to the global trend. However, the fluctuations in the findings are extremely clear. They could be due to the low number of German life science articles in the database - less than 10,000 until the end of the $1980 \mathrm{~s}$. However, this cannot be the only reason why we measured a proportion of $1.4 \%$ in 1998 , for example, while two years later this figure was $3.1 \%$, before it decreased again in 1992 to $2 \%$.

In 2005 the proportion of German articles with a question mark in the life sciences lay at almost $3 \%$, which was well above the global average of around $2.3 \%$. 
BALL: Scholarly communication in transition

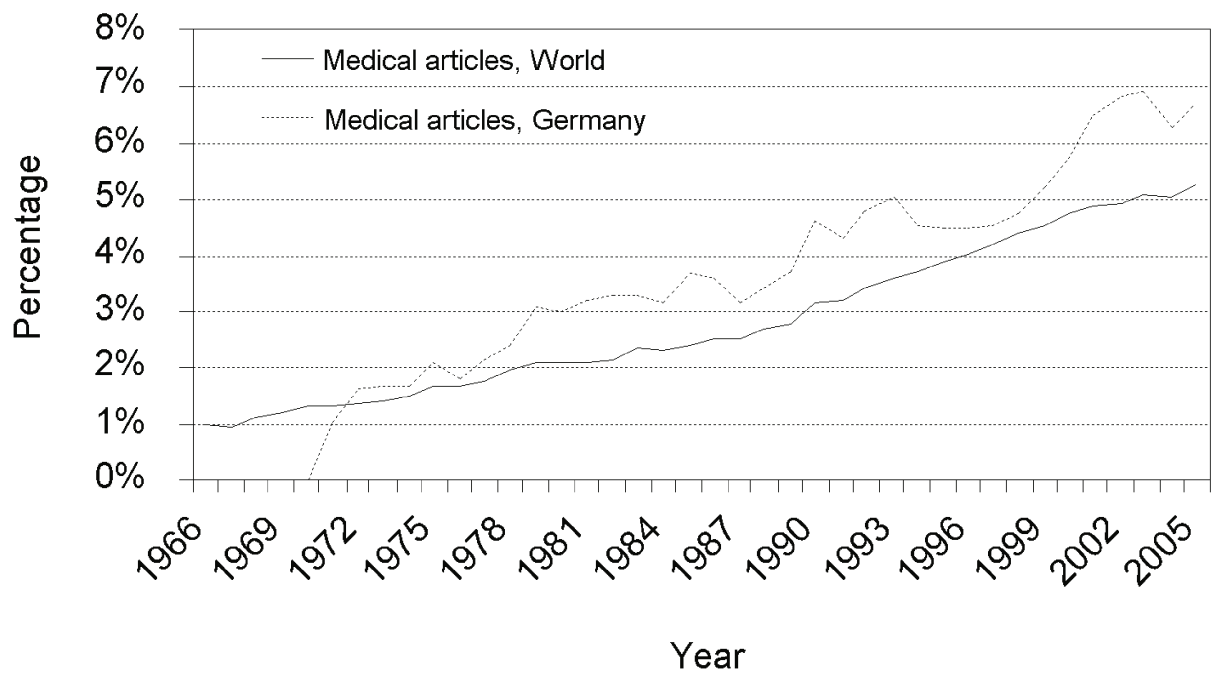

Figure 4. In medicine an increase of the same order as the global average could be determined

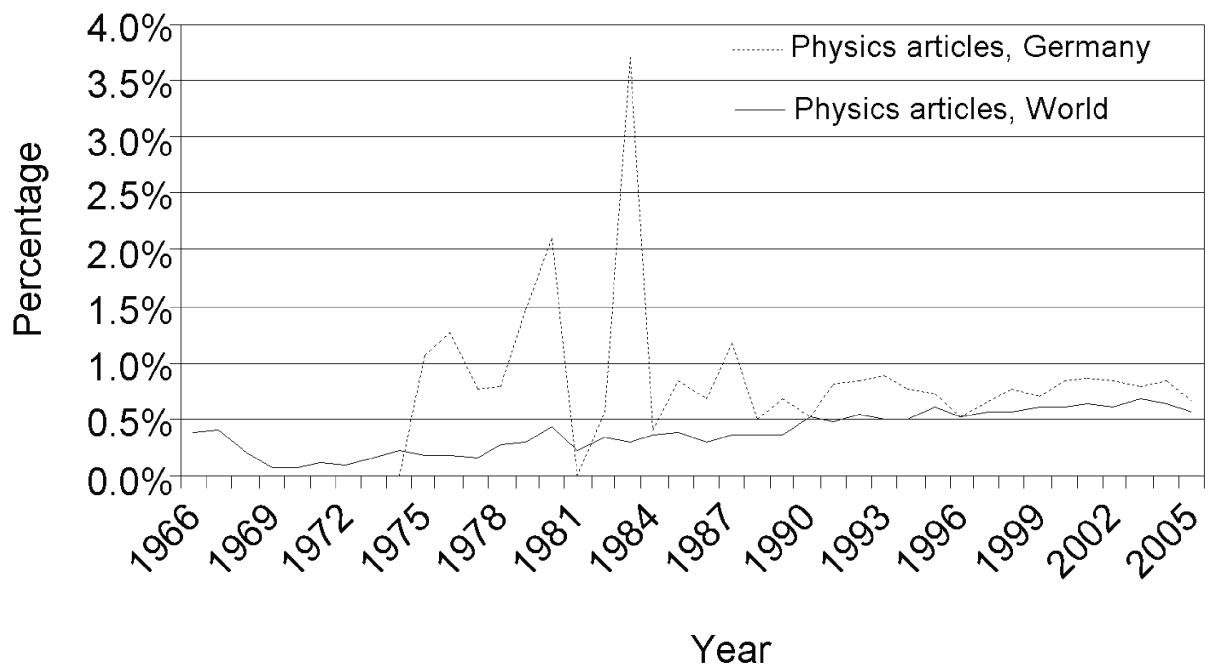

Figure 5. A completely different situation was observed for question-mark physics articles 
Table 1. While the global average number of articles with question marks in their titles increased slowly but surely, physics articles from Germany experienced extreme fluctuations, particularly between the years of 1975 and 1990. One of the main reasons for this can be attributed to the very small sample for this period

\begin{tabular}{|c|c|}
\hline Year & Question-mark articles in Germany \\
\hline 1966 & 0 \\
\hline 1967 & 0 \\
\hline 1968 & 0 \\
\hline 1969 & 0 \\
\hline 1970 & 0 \\
\hline 1971 & 0 \\
\hline 1972 & 6 \\
\hline 1973 & 45 \\
\hline 1974 & 123 \\
\hline 1975 & 94 \\
\hline 1976 & 79 \\
\hline 1977 & 129 \\
\hline 1978 & 127 \\
\hline 1979 & 136 \\
\hline 1980 & 142 \\
\hline 1981 & 225 \\
\hline 1982 & 173 \\
\hline 1983 & 189 \\
\hline 1984 & 250 \\
\hline 1985 & 234 \\
\hline 1986 & 147 \\
\hline 1987 & 168 \\
\hline 1988 & 810 \\
\hline 1989 & 1508 \\
\hline 1990 & 2439 \\
\hline 1991 & 2719 \\
\hline 1992 & 2706 \\
\hline 1993 & 3344 \\
\hline 1994 & 3997 \\
\hline 1995 & 3833 \\
\hline 1996 & 12367 \\
\hline 1997 & 13109 \\
\hline 1998 & 14103 \\
\hline 1999 & 14770 \\
\hline 2000 & 14290 \\
\hline 2001 & 12087 \\
\hline 2002 & 12239 \\
\hline 2003 & 15743 \\
\hline 2004 & 15977 \\
\hline 2005 & 15941 \\
\hline
\end{tabular}

A completely different situation was observed for physics (Figure 5).

While the global average number of articles with question marks in their titles increased slowly but surely, physics articles from Germany experienced extreme 
fluctuations, particularly between the years of 1975 and 1990. One of the main reasons for this can be attributed to the very small sample for this period (Table 1).

Only from 1990 on did the absolute number of German physics articles in the SCOPUS database increase to more than 2,000. Until that point, the sample only consisted of a few hundred articles, out of which very few individual papers with question marks could be found. Therefore, we do not consider the results at the beginning of the measurement period as relevant and we only compare the data from 1990 on. From this point in time on, a parallel development can be observed between question-mark articles from Germany and the global average. The figures also lie very close to the global average and in 2005 they reach $0.75 \%$, while the global average is around $0.53 \%$.

\section{Discussion}

The analysis we conducted revealed that formulating the titles of scientific publications as questions is increasingly becoming a widespread phenomenon. The increases measured are in fact so significant that we can speak of a general trend. In medicine today, one in twenty articles has a question-mark title - this is more than $5 \%$ of all articles. In absolute terms, this means that in 2005, we recorded more than 23,000 of these articles, while in 1970 we only registered around 2,000. This is not a random phenomenon in the other sciences either; while there were only 800 question-mark articles in the life sciences in 1980, there are more than 8,000 today.

Only in physics does the absolute and relative number of question-mark articles tend to be low: in 1970, we only found 20 articles worldwide with question marks, while today (2005) there are around 900.

We are quite apparently dealing with a phenomenon of mass communication on the one hand, since the language used in the natural sciences cannot be separated from general linguistic developments. On the other hand, however, we believe that the phenomenon of the question mark is connected to a scientifically inherent development.

Such a clear increase in the use of question marks in the formulation of titles for scientific articles is a clear sign for us of changed scholarly communication that also manifests itself in the structure of titles. Haggan (2004) wrote that the title in science increasingly serves a marketing purpose. Titles "characteristically set out to attract the reader through a kind of verbal flirtation, enticing the reader with suggestive and tantalisingly enigmatic hints of the delights that follow". [25]

Since the question mark is generally used as a rhetorical device in titles, we can explain the heavy use of the question mark in titles by means of different motivations:

- To formulate the central issue of the study: The title often formulates the intrinsic scientific question that the publication is based on. Such use of the 
question mark is the least influenced by marketing strategies and can be understood as a "serious" scientific front matter. (Is it appropriate to use structured abstracts in social science journals? [26] Are action and perception in near and far space additive or interactive factors? [27]).

- To stimulate interest: We could effectively assume that the author has either chosen to use a question mark to deliberately provoke the reader (Don't take any virtual planes! Reply to Powers on Harnad on SymbolismConnectionism [28], The "Hawthorne effect" is a myth, but what keeps the story going? [29], Greece's tobacco policy: another myth? [30]) or they have deliberately chosen an ambiguous or clearly "excessive" title to generate interest (Studying the brain drain: Can bibliometric methods help? [31], Science at the supermarket: A comparison of what appears in the popular press, experts' advice to readers, and what students want to know [32], Can a machine be conscious? How? [33]).

In this case, the question mark saves the author in that it relativises his/her "excessive" claims in the title and he/she can refer to it. To a certain extent, the question mark functions like an apology for having promised too much. In this sense, the question mark is used as a stylistic device to express the "scientific propriety" that the author deliberately sacrificed in the title in favour of attracting attention more quickly.

- To express the dubious nature of results: In the "publish or perish" race, authors must increasingly get their results out into the "market" of scholarly communication at a very early stage. Often results are published before they have actually been explored in the necessary depth and therefore before they can be $100 \%$ verified. In such cases, the author secures first publication by occupying a topic without having valid data at his/her disposal. The question mark in an article title is therefore an elegant way of publishing vague data and findings on the one hand, and on the other, of remaining unassailable: (No postnatal doubling of number of neurons in human Broca's areas? A stereological study[34]). The widespread use of the question mark clearly correlates with the increasing competition in science and research.

The different distribution of question-mark articles in the disciplines of medicine, life sciences and physics is also a clear phenomenon. The perfectly clear showing in medicine, in particular, allows us to draw conclusions regarding different habits in scholarly communication. It would appear that the motivations outlined above behind the use of question-mark titles apply more to medical scientists that to scientists working in the life sciences or even physics. This can be explained by the closeness of medicine to natural language, on the one hand, and on the other by a much higher degree of pressure (and/or higher personal motivation) compared to other disciplines to 
be the first author to describe new diseases, diagnoses and therapies. This is clearly less of a factor in the life sciences and only marginally figures in physics. An exhaustive answer to the differences between the disciplines has yet to be found and it is still a research desideratum.

We also managed to identify national and regional differences in the use of the question mark in titles through our analysis of German articles. We believe that the influence of the respective native language and its characteristics should not be excluded as a factor in the use of the question mark as a stylistic device, although this must be relativised for scientific articles that are predominantly published in the English language. The increased usage of the English language instead of the native language over the last 30 years would also tend to contradict this trend.

Further studies are required in this area in order to analyse in more detail whether and how language and nationality are related to the use of the question mark in the titles of scientific publications.

I would like to thank Dirk Tunger, Research Centre Jülich, Central Library, for performing the data searches used in this analysis

\section{References}

1. G. Lewison, J. Hartley, What's in a title: Numbers of words and the presence of colons, Scientometrics, 63 (2005) 341-356.

2. L. AdAms-Phillips, C. BARRY, J. GIOVANNONI, Signal trasduction systems regulatin fruit ripening, Trends Plant Science, 9 (2004) 331-338.

3. C. Ross, Huntington's disease new paths to pathogenesis, Cell, 118 (2004) 4-7.

4. T. Tyrrell, R. E. ZeEBE, History of carbonate ion concentration over the last 100 million years, Geochimica et Cosmochimica Acta, 68 (2004) 3521-3530.

5. G. Krapivinsky, I. Medina, L. Krapivinsky, S. Gapon, D. Clapham, SynGAP-MUPP1-CaMKII synaptic complexes regulate p38 MAP kinase activity and NMDA receptor- dependent synaptic AMPA receptor potentiation, Neuron, 43 (2004) 563-574.

6. All examples taken from: Top 25 Hottest Articles, http://top25.sciencedirect.com/index.php?cat_id=6\&subject_area_id=2

7. W. SChNEIDER, D. EssLingER, Die Überschrift, List Verlag, München, 2002.

8. M.A. MABE, M. AMIN, Dr. Jekyll and Dr. Hyde: Author-reader asymmetries in scholarly publishing. In: ASLIB Proceedings, 54 (3). Emerald Group Publishing Limited, 2002 pp.149-157.

9. B. SIMON, Der Teaser - eine multifunktionale Textsorte, Dissertation (2004) 129. 134-139.

10. G. MYERS, The pragmatics of politeness in scientific articles. Applied Linguistics 10 (1989) 1-35.

11. M. YITZHAKI, Relations of title length of journal articles to number of authors, Scientometrics, 30 (1994) 321-332.

12. J. A. PERry, The Dillion hypothesis of titular colonicity: En empirical test from the ecological science, Journal of the American Society for Information Science, 36 (1985) 251-258.

13. M. TOWNSEND, Tutular colonicity and scholarship - New-Zealand research and scholarly impact, New Zealand Journal of Psychology, 12 (1983) 41-43. 
14. J. T. Dillon, The emergence of the colon: An empirical correlate of scholarship, American Psychologist, 36 (1981) 879-884.

15. J. HaRtley, Planning that title: Practices and preferences for titles with colons in academic articles, Library \& Information Science Research, 29 (2007) 553-568.

16. V. SOLER, Writing titles in science: An exploratory study, English for Specific Purposes, 26 (2007) 90. $100-102$.

17. A. Alexandrov, M. Hennerici, Writing good abstracts, Cerebrovascular Diseases, 23 (2007) 256-259.

18. D. H. Rakison, J. B. Cicchino, Is an infant a people person?, Cognition, 94 (2004).

19. V. A. Kuhlmeier, P. Bloom, K. Wynn, Do 5-month-old infants see humans as material objects?, Cognition, 94 (2004) 95-103.

20. G. NAtOLI, Little things that count in transcriptional regulation, Cell, 118 (2004) 406-408.

21. M. L. MBOw, R. T. SARISKY, What is disrupting IFN- $\alpha$ 's antiviral activity?, Trends in Biotechnology, 22 (2004) 395-399.

22. S. G. Fischer, W. D. Macrosson, C. A. WALker, FIRO-B, the power of love and the love of power, Psychological Reports, 76 (1995) 195-206.

23. N. Rosen, Q. B. SHE, AKT and cancer - is it all mTOR?, Cancer Cell, 10 (2006) 254-256.

24. D. L. Simmons, What makes a good anti-inflammatory drug target?, Drug Discovery Today, 11 (2006) 210-219.

25. M. HAGGAN, Research paper titles in literature, linguistics and science: dimensions of attractions, Journal of pragmatics, 36 (2004) 293-317.

26. J. HARTLEY, Is it appropriate to use structured abstracts in social science journals?, Learned Publishing, 10 (1997) 313-317.

27. P. H. Weiss, J. C. Marshall; K. Zilles, G. R. FinK, Are action and perception in near and far space additive or interactive factors?, Neurolmage, 18 (2003) 837-846.

28. S. HARNAD, Don't take any virtual planes! Reply to powers on hornad on symbolism-connectionism, Psycoloquy, 12 (2001) Article 24.

29. M. A. J. KOMPIER, The "Hawthorne effect" is a myth, but what keeps the story going?, Scandinavian Journal of Work, Environment \& Health, 32 (2006) 402-412.

30. C. I. VARDAVAS, A. KAFATOS, Greece's tobacco policy: another myth?, Lancet, 367 (2006) 1485-1486.

31. G. LAUDEL, Studying the brain drain: Can bibliometric methods help?, Scientometrics, 57 (2003) $215-237$.

32. C. Zimmermann, G. L. Bisanz, J. Bisanz, J. S. Klein, P. Klein, Science at the supermarket: A comparison of what appears in the popular press, experts' advice to readers, and what students want to know, Public Understanding of Science, 10 (2001) 37-58.

33. S. HARNAD, Can a machine be conscious? How? www.cogprints.org/5330, (2003).

34. H. B. Uylings, L. I. Malofeeva, I. N. Bogolepova, A. M. Jacobsen, K. Amunts, K. Zilles, No postnatal doubling of number of neurons in human Broca's areas? A stereological study, Neuroscience, 136 (2005) 715-728. 